\title{
Uma experiência de formação de professores em torno do conhecimento histórico-educacional na Universidade Federal de Uberlândia
}

\author{
An experience in teacher training in regard to historical- \\ educational knowledge at the Universidade Federal de Uberlândia
}

Décio Gatti Júnior ${ }^{\star 1}$

RESUMO

Este artigo reflete sobre uma experiência de ensino da disciplina História da Educação em cursos de formação de professores na Universidade Federal de Uberlândia entre 1994 e 2014. Em termos internacionais e nacionais, a disciplina tem alcançado sucesso no âmbito da investigação, mas, no âmbito do ensino, observa-se que ela sofre redução de carga horária, ou mesmo desaparece dos currículos. Uma experiência de ensino que, a princípio, tem alcançado êxito, soma esforços de construção de um programa disciplinar ajustado aos interesses dos alunos e que se conjugue aos propósitos formativos. Depreendem-se dessa experiência de ensino as potencialidades advindas do emprego de diferentes fontes de informação, tais como textos, filmes e iconografia, sob um eixo articulador, que tem conseguido estimular o interesse dos alunos, vencendo preconceitos e levando-os a apoiar a permanência da disciplina nos currículos de formação de professores.

Palavras-chave: História; educação; ensino.

\section{Abstract}

This paper is a reflection on the experience of teaching the subject of History of Education in teacher education courses at the Universidade Federal de Uberlândia (MG, Brazil) from 1994 to 2014. Internationally and in Brazil, the subject has achieved success in the field of investigation but, in the field of teaching, it has undergone reduction in class time and, in the most serious cases, it has disappeared from the curriculum. Thus, reflection on a teaching experience that has achieved success is increasingly significant upon joining efforts in building up a course program fitted to the interests of students and that combines with educational purposes. This teaching experience shows the potential of using different sources of information, such as texts, films, and iconographic resources that revolve around a common axis, and this approach has been able to stimulate the interest of students, overcome prejudice, and lead students to support continuity of the discipline in the teacher education curricula.

Keywords: History; education; teaching.

\footnotetext{
* Pós-doutorado em Educação. Professor Titular, Faculdade de Educação, Universidade Federal de Uberlândia (UFU). Bolsista de Produtividade em Pesquisa CNPq. Beneficiário do Programa Pesquisador Mineiro, Fapemig. Uberlândia, MG, Brasil. degatti@ufu.br
} 
Entre 1994, época de meu ingresso na Universidade Federal de Uberlândia (UFU), e 2010, a maior parte de minha atuação no ensino de graduação esteve ligada ao ensino da disciplina História da Educação no curso de Pedagogia. Desde 2012, todavia, tenho tido a experiência de lecionar a disciplina para alunos do curso de licenciatura em Educação Física e, no segundo semestre de 2014, na licenciatura em Enfermagem. Há, porém, muita diferença entre lecionar a disciplina História da Educação no curso de Pedagogia e nas demais licenciaturas. Primeiramente, pelo fato de no curso de Pedagogia, o conteúdo histórico-educacional ser desenvolvido em 180 horas, em quatro semestres consecutivos, ao passo que nas demais licenciaturas a disciplina tem carga horária limitada a 60 horas, ocupando apenas um semestre letivo. Em segundo lugar, se para os alunos de Pedagogia nem sempre é fácil demonstrar a importância da disciplina, já que eles tendem a preferir a proximidade com conteúdos mais instrumentais da profissão docente, imagine-se a dificuldade dessa mesma demonstração para alunos que frequentam cursos ligados à prática esportiva e ao atendimento à saúde.

Assim, ao deparar, em 2012, com a necessidade de lecionar a disciplina com carga horária total de 60 horas, tive de me empenhar na construção de um curso que tivesse a capacidade de despertar o interesse dos alunos. Ao invés de construir um curso fechado logo à partida, optei por ouvir os alunos antes, com exame de suas impressões sobre a disciplina de História e, particularmente, de suas expectativas sobre cursar uma disciplina de História da Educação. Com poucas exceções, os alunos revelaram o desapreço pela disciplina e por seus conteúdos, assim como pela forma habitual das aulas.

Como enfrentar essa barreira? Como transformar algo que é extremamente sedutor para mim - que não só ensino a disciplina, mas que também me dedico, há muitos anos, à produção de conhecimentos novos, à orientação de alunos em iniciação científica, no mestrado e no doutorado - em algo que não seja enfadonho para um público carregado de preconceitos em relação àquela disciplina e àqueles conhecimentos? A resposta a essa questão foi buscada no cotejamento de conteúdos relevantes para os alunos e que também respondessem às necessidades de formação de futuros professores, com a utilização de fontes de informações variadas, textos, imagens iconográficas e cinematográficas. 


\section{MODERNIDADE, DIREITOS HUMANOS, ESCOLA E INCLUSÃO DIFERENCIADA: TEXTOS E FILMES}

As duas primeiras unidades do programa da disciplina de História da Educação, de um total de três, estão ancoradas na ideia de valorizar conteúdos que buscassem compreender a escola como uma das instituições fundamentais da Modernidade, na qual o indivíduo, por uma ação intencional e ligada a finalidades sociais mais amplas, tornar-se-ia cidadão. ${ }^{2}$ Nessas unidades, busca-se promover a contextualização histórica e o esforço de conceptualização em torno da temática da Modernidade, da relação dela com a construção de uma sociedade de direitos, com a institucionalização da educação escolar, em meio a um projeto de civilização e de estratégias de inclusão diferenciada.

Sem dúvida, são conteúdos áridos para o trabalho em sala de aula, mas o esforço docente foi grande na escolha de materiais de apoio que facilitassem o ingresso nas temáticas, incluindo texto de autoria do próprio professor, mas, também, bibliografia de referência importante na área de História e de História da Educação, com textos de autores estrangeiros e brasileiros. Ao lado desses materiais impressos, houve ainda a escolha de alguns filmes que poderiam ajudar não só no entendimento dos conteúdos, mas também em uma estratégia de aproximação dos alunos, com ampliação do interesse pela disciplina, dada a familiaridade dos jovens com a linguagem cinematográfica.

No que se refere aos filmes, partiu-se da ideia da existência de um fenômeno da cultura geral que tem contribuído para o conhecimento dos direitos humanos por todos: o cinema. ${ }^{3}$ Embora outras manifestações culturais também contribuam, tais como a música, a fotografia, o teatro e a pintura, nenhuma delas tem o impacto de massa do cinema. Seja porque os filmes atraem grande público em todo o mundo, sendo dublados e legendados para diversas línguas, seja porque ampliam seu público quando adaptados e transmitidos pela televisão, ou ainda quando são disponibilizados por meio dos antigos sistemas VHS e DVD e, mais recentemente, Blu-ray Disc e mesmo pela empresa Netflix, que oferece serviço de TV pela internet.

Os filmes podem ativar emoções e reflexões em seu público, e assim têm conseguido apresentar acontecimentos condenáveis de agressão aos direitos humanos, contribuindo para formatar atitudes individuais e coletivas de busca da justiça, em conformidade com esses direitos. ${ }^{4}$ 
A primeira unidade da disciplina de História da Educação, intitulada "Modernidade, sociedade de direitos e educação escolar", congrega um texto de minha autoria, intitulado "A construção de uma sociedade de direitos: história, livro didático e cinema”, que apresenta a temática aos alunos (Gatti Jr., 2010), e alguns filmes que podem ser exibidos e discutidos em sala de aula, conforme o momento e a disposição dos alunos. ${ }^{5}$ A seguir, estão elencados, em ordem cronológica de lançamento, os filmes em referência. O primeiro deles tem o título original em inglês Mr. Smith Goes to Washington (no Brasil, A mulher faz o homem). É um filme norte-americano de 1939, dirigido por Frank Capra, baseado em texto de Lewis R. Foster, com roteiro de Sidney Buchman e estrelado por James Stewart (Jefferson Smith), Jean Arthur (Clarissa Saunders), Claude Rains (senador Joseph Harrison Paine), Edward Arnold (Jim Taylor), Guy Kibee (governador Hubert “Happy” Hopper) etc.

O filme aborda a ida de Jefferson Smith - líder dos escoteiros de uma pequena cidade do interior dos Estados Unidos - ao Senado, em Washington. A intenção, ao indicá-lo, é que fosse manipulado por políticos e empresários poderosos de seu estado de origem. No entanto, o plano falha, dado que o senador Smith não consegue compactuar com a corrupção e atrapalha os planos daqueles que o indicaram. Logo no início do filme são ditas estas palavras:

Jim Taylor (empresário poderoso): Um caçador de esquilos para o Senado?

Governador Hubert "Happy” Hopper: Ele é um simplório, um patriota ingênuo. Cita Lincoln e Washington de cor. E fica em posição de sentido para o governador. Até resgata garotos e gatos.

Ocorre que o "patriota ingênuo" elabora um projeto que visa construir, em sua cidade, um acampamento gigantesco para os jovens de todo o país sem usar dinheiro público, mas apenas doações dos pais deles, o que, sem saber, afeta os planos de poderosos locais para a construção de uma represa naquela área, com consequente valorização das terras do entorno. 


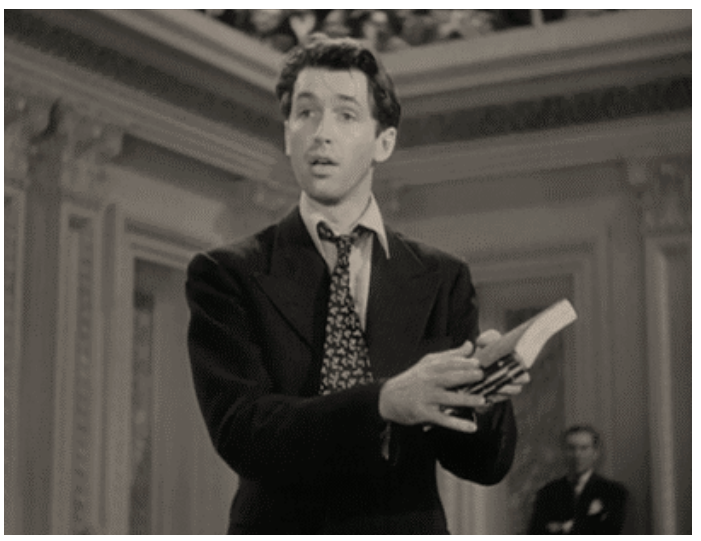

Figura 1 - O ator James Stewart interpreta Jefferson Smith em A mulher faz o homem (1939).

O senador Smith enfrenta uma campanha terrível feita para desmoralizá-lo, articulada pelo empresário Jim Taylor em conluio com o governador e o outro senador pelo mesmo estado, Joseph Harrison Paine, o que poderia levá-lo a ser expulso do Senado. Como forma de garantir o direito à defesa, toma a palavra no Senado, e, pelas regras regimentais, não poderia ter sua palavra cassada enquanto permanecesse falando e em pé. Ao longo de seu discurso, que alcança mais de 23 horas, o senador Smith faz a leitura de diversos documentos fundamentais para os Estados Unidos e críticas muito duras aos desvios que considera estarem ocorrendo em relação ao seu conteúdo.

Senador Jefferson Smith: Vida, Liberdade e Busca da Felicidade. Para assegurá-los, instituem-se governos, de onde os homens extraem seus poderes legítimos e, quando o governo torna-se destrutivo a seus fins, é direito do povo alterá-lo ou aboli-lo ... Sempre gostei dessa parte da Declaração de Independência. Não há país que faça com que essas regras funcionem sem homens que tenham aprendido o que são os direitos humanos ... Não se pode comprometer a verdade ... Façam alguma coisa. Levantem-se como aquela dama no alto do Capitólio. A dama que representa a liberdade. Olhem o país pelos olhos dela, se quiserem ver algo. E não verão apenas a paisagem. Verão um desfile do que o homem fez para si após séculos de luta. Luta por algo melhor do que a lei da selva. Luta para que o homem possa ficar em pé, livre e decente como foi criado. Independentemente de raça, cor ou credo ... Não há lugar para a propina e a ganância, ou mentiras ou 
comprometimento das liberdades humanas. Se for isso que os adultos fizeram com o mundo, devemos fazer os acampamentos e ver o que os garotos fazem. Não é tarde demais.

Esse filme, quando exibido em sala de aula, inicialmente provoca estranhamento, sobretudo pela época histórica que evoca e pelo caráter ficcional e crítico que contém, dado que despertou grandes polêmicas na época de seu lançamento. No entanto, no que se refere à disciplina, ele colabora para o entendimento do conteúdo das primeiras declarações de direitos inglesa, americana e francesa, bem como do papel da educação escolar na institucionalização da nova ordem liberal desde o final do século XIX até a época atual.

Outro filme muito interessante que venho exibindo em sala de aula tem seu título original em inglês 12 Angry Men (1957; no Brasil, Doze homens e uma sentença), dirigido por Sidney Lumet sobre roteiro de Reginald Rose. É uma adaptação de versão feita para a televisão em 1954, e teve refilmagens realizadas em 1997, 2004-5 e 2006-7. É estrelado, na versão de 1957, por Henry Fonda (Jurado 8), Lee J. Cobb (Jurado 3), Robert Webber (Jurado 12), Martin Balsam (Jurado 1, presidente do júri) e Ed Begley (Jurado 10), entre outros. Aborda o julgamento de um jovem de origem hispânica na cidade de Nova York que foi acusado de ter matado seu próprio pai. O tribunal do júri é instalado e 12 jurados terão de decidir o veredito. No início do filme o juiz se manifesta:

Juiz fala aos membros do júri: ... Ouviram um longo e complexo caso de homicídio em Primeiro Grau. Um homicídio premeditado é a mais grave acusação em nossos tribunais. Ouviram os testemunhos. A lei lhes foi exposta para ser aplicada ao caso. Agora é dever de vocês tentarem separar os fatos da versão. Um homem está morto. A vida de outro está em jogo. Se houver dúvida razoável sobre a culpa do acusado ... devem entregar-me o veredito de inocente. Se, entretanto, não houver, devem, em sã consciência, declarar o acusado culpado. O que quer que decidam, o veredito deve ser unânime. No caso de julgarem o acusado culpado, o tribunal não considerará a hipótese de perdão. A sentença de morte é compulsória neste caso. Estão frente a grande responsabilidade.

Na sala de reuniões do júri, lugar onde se passam quase todas as cenas do filme, inicialmente parecia existir convergência de opiniões quanto à culpa do réu. Porém, o Jurado 8, interpretado por Henry Fonda, está em dúvida e, como a decisão tem de ser unânime, a situação do júri torna-se complicada. Aos 
poucos, mediante discussões sempre muito tensas, os jurados vão mudando de opinião.

No decorrer das argumentações entre os membros do júri, ocorre discussão memorável, em que um dos jurados expressa seu ponto de vista aos demais. No entanto, ele faz um discurso altamente preconceituoso em relação ao acusado, fazendo que a maioria dos jurados se levante da mesa, postando-se de costas para o orador, em cenografia que demonstra a dificuldade dos jurados em aceitar argumentos daquela natureza.

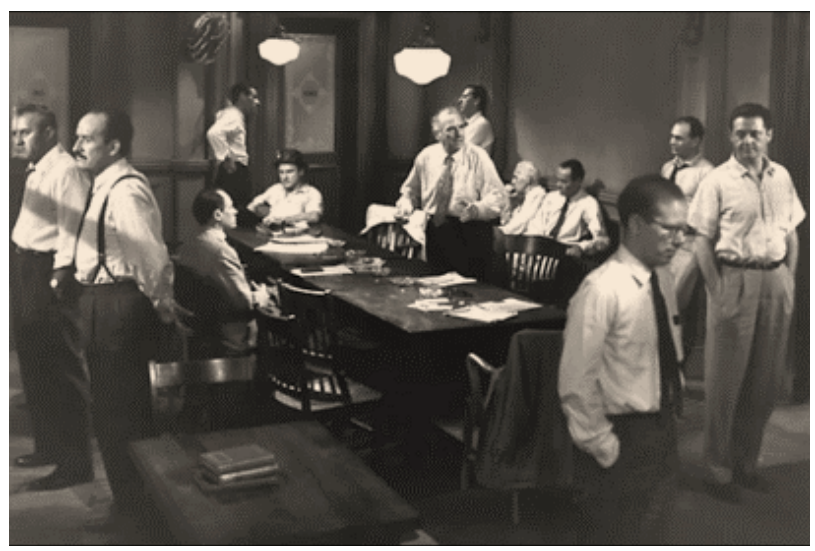

Figura 2 - Cena do filme Doze homens e uma sentença (1957).

Jurado: Eu não entendo vocês! Esses detalhezinhos não significam nada! Viram o rapaz tanto quanto eu ... Sabem como essa gente mente! Já é uma coisa nata. Que diabos! Não preciso dizer. Eles não sabem o que é verdade. E não precisam de motivo para matar alguém. Ficam bêbados. Bebem como gambás. Todos eles! ... É o modo como são. Entende? Violentos! ... A vida humana não significa o mesmo para eles. Eles só vivem enchendo a cara e brigando. E se alguém morrer, morreu! Não ligam. Claro que possuem coisas boas. Sou o primeiro a reconhecer. Conheço um casal que era bom, mas é exceção. Entendem? A maioria parece insensível. São capazes de tudo ... O rapaz é mentiroso! Sei tudo sobre eles.

Diante da reação da maior parte dos membros do júri, o Jurado 8, responsável pela longa discussão em torno do veredito, faz esta reflexão:

Jurado 8: É sempre difícil deixar os preconceitos fora de uma questão dessas. Não importa para que lado vá, o preconceito sempre obscurece a verdade. [Nesse 
caso] Não sei qual é a verdade. Suponho que ninguém aqui jamais saberá de fato. Nove pessoas aqui parecem achar que o réu é inocente. Mas só estamos jogando com probabilidades. Podemos estar enganados. Podemos estar deixando um homem culpado livre, não sei. Ninguém pode saber ao certo. Mas temos dúvida razoável. E isso é algo que é valioso em nosso sistema. Nenhum júri pode declarar um homem culpado a menos que tenha certeza.

Sem dúvida, o filme colabora para o conhecimento, pelos alunos, de dispositivos importantes da doutrina dos direitos humanos, em especial daqueles contidos na Declaração Universal dos Direitos Humanos, que dizem respeito à igualdade entre os homens e ao combate aos preconceitos de ordem racial e étnica. Isso coincide com o melhor entendimento da legislação sobre o ensino no Brasil, destacadamente, no período iniciado com a promulgação da Constituição de 1988, que embasa a legislação educacional e os conteúdos a serem disseminados nas escolas do país.

Outro filme que tenho exibido em sala de aula intitula-se Philadelphia (no Brasil, Filadélfia). Filme de 1993, foi dirigido por Jonathan Demme, e seu roteirista, Ron Nyswaner, é um ativista dos direitos dos homossexuais que, frequentemente, tem trabalhado com temáticas relacionadas à homossexualidade, a homofobia e a aids. Filme estrelado por Tom Hanks (Andrew Beckett), Denzel Washington (Joe Miller), Jason Robards (Charles Wheeler) e Antonio Banderas (Miguel Álvarez), tendo recebido diversos prêmios nacionais e internacionais.

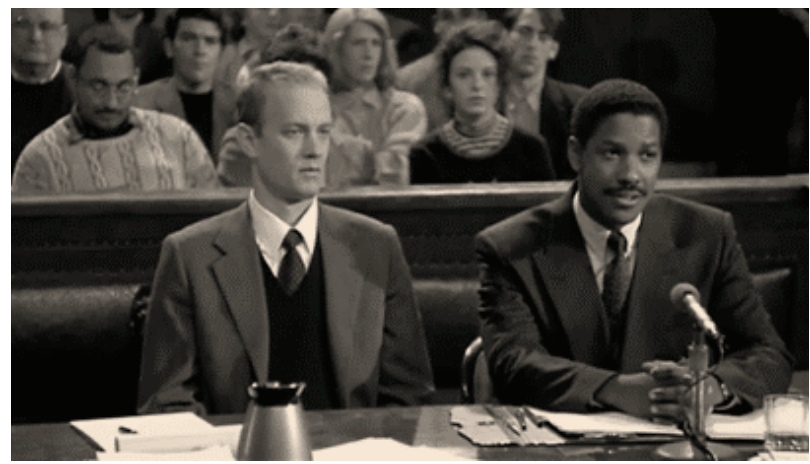

Figura 3 - Andrew Beckett (Tom Hanks) à esquerda

e Joe Miller (Denzel Washington) à direita, em cena no tribunal durante o filme Filadélfia (1993). 
O filme narra a situação vivida por um advogado promissor que trabalha em um importante escritório da Filadélfia, mas que é despedido quando descobrem ser ele portador do vírus da aids. Com muita dificuldade, ele consegue contratar os serviços de um advogado negro, o qual é forçado a encarar seus próprios preconceitos para defendê-lo. Durante as cenas que se passam no tribunal, o advogado de defesa e seu cliente travam o seguinte diálogo:

Joe Miller: Você é um bom advogado?

Andrew Beckett: Sou um excelente advogado.

Joe Miller: Por que é excelente?

Andrew Beckett: Eu amo a lei. Conheço a lei. Eu sou excelente praticando-a.

Joe Miller: O que ama na lei, Andrew?

Andrew Beckett: Muitas coisas. O que eu mais amo na lei?

Joe Miller: Sim.

Andrew Beckett: É que, de vez em quando, não com frequência, mas ocasionalmente, pode-se participar da justiça sendo feita. Isto é emocionante quando acontece.

Esse filme, quando exibido - o que pôde ocorrer, em especial, para os alunos da disciplina História da Educação do curso de Enfermagem -, colabora para o entendimento de princípios fundamentais da doutrina dos direitos humanos. Além disso, tem um caráter educativo para a melhor compreensão dos direitos dos homossexuais, colaborando também para o combate à homofobia, elementos importantes para a formação da cidadania, preconizados em legislação internacional e, também, em legislação brasileira, sobretudo a partir da década de 1990.

Outro filme que por vezes foi exibido ao longo dos últimos anos na disciplina de História da Educação tem o título em inglês A Time to Kill (1996; no Brasil, Tempo de matar), dirigido por Joel Schumacher, com roteiro adaptado por Akiva Goldsman a partir de livro homônimo escrito por John Grisham e publicado em 1989. Estrelado por Matthew McConaughey (Jake Brigance), Sandra Bullock (Ellen Roark), Samuel L. Jackson (Carl Lee Hailey), Kevin Spacey (Rufus Buckley) e Dwayne Looney (Chris Cooper). 


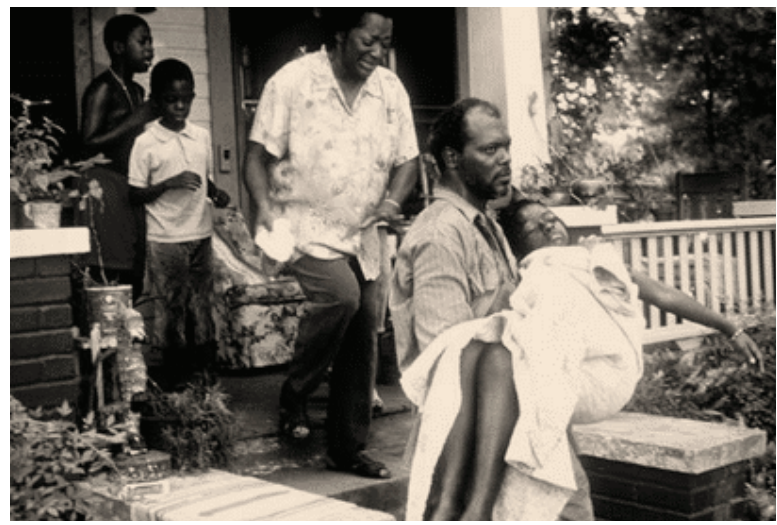

Figura 4 - Cena do início do filme Tempo de matar (1996).

Carl Lee Hailey (Samuel L. Jackson) leva sua filha, que havia sido estuprada por dois homens brancos racistas, até a ambulância.

O filme narra a história de Carl Lee Hailey, um pai de família negro que cometeu duplo homicídio e feriu um policial (Dwayne Looney) na entrada do tribunal onde os dois homens que matou seriam julgados pelo crime de terem estuprado sua filha de 10 anos. Os estupradores eram brancos racistas e, no momento do crime, estavam bastante embriagados. O fato aconteceu na cidade de Canton, no Mississippi, nos Estados Unidos. Todos os membros do júri eram homens e mulheres brancos, estando, a princípio, inclinados a votar pela culpa do acusado. $\mathrm{O}$ advogado de defesa, Jake Brigance, e sua equipe sofrem muita pressão para abandonar o caso que ganhou contornos raciais nítidos, com envolvimento de adeptos da Ku Klux Klan, grupo racista de extrema direita norte-americano. Mesmo assim, seguem com o caso e vão ao tribunal. Nele, por insistência de Carl Lee Hailey, Jake Brigance (advogado de defesa) interroga uma das testemunhas da acusação, quando travam o seguinte diálogo:

Jake Brigance: Detetive Looney. Acha que Carl Lee o atingiu de propósito?

Dwayne Looney: Não, senhor. Foi um acidente.

Jake Brigance: Acha que ele deve ser punido?

Dwayne Looney: Não, senhor. Não alimento nenhum rancor por ele. Ele fez o que eu teria feito.

Jake Brigance: $\mathrm{O}$ que quer dizer com isso? 
Dwayne Looney: Que não o culpo pelo que fez. Aqueles dois estupraram sua filha ... Eu tenho uma filhinha. Se alguém a estuprar, mato o cachorro, estouro ele como Carl Lee fez. Ele é um herói. Libertem-no! Libertem-no! Libertem-no!

É evidente que se trata de um diálogo que não contribuiu para a argumentação da acusação, pois, apesar de o julgamento ser de um duplo homicídio impetrado por Carl Lee Hailey a dois homens que eram réus confessos pelo estupro de sua filha, o depoimento do policial Dwayne Looney trouxe ao tribunal a memória viva do crime cometido pelos dois homens brancos assassinados, o que, de pronto, causou comoção aos membros do júri e aproximação com a causa da defesa. Mesmo assim, predomina a inclinação do júri à condenação do réu. A reversão do veredito desfavorável ao réu parece improvável, até que em uma conversa na prisão entre o advogado de defesa e seu cliente, o segundo insiste em que a única possibilidade de se livrar da acusação passa, necessariamente, por ter um homem branco em sua defesa, em especial em um tribunal predominantemente branco. Assim, a partir dessa conversa, o advogado de defesa muda sua forma de abordar o caso, utilizando sua fala final ao júri para tentar uma nova linha de defesa. Pede aos membros do júri que fechem os olhos e narra com riqueza de detalhes os fatos relacionados ao estupro de uma menina por dois homens, só que, ao final da história, ao invés de dizer que se trata da filha de Carl Lee Hailey, pede que imaginem tratar-se de uma menina branca. Em seguida, faz uma fala aos membros do júri que reproduzimos a seguir, mediante a qual consegue a absolvição do réu.

Jake Brigance: Que parte de nós busca a verdade? Nossa mente ou nosso coração? Eu quis provar que um negro podia ser julgado com justiça no Sul. Que somos todos iguais aos olhos da lei. Não é verdade, porque os olhos das leis são humanos. Os de vocês e os meus. E até podermos nos ver como iguais, a justiça nunca será imparcial. Ela continuará sendo um reflexo de nossos preconceitos. Até lá, temos o dever, perante Deus, de buscar a verdade. Não com nossos olhos e mentes, porque o medo e o ódio fazem surgir preconceitos de convívio, mas com nossos corações, onde a razão não manda.

Depreende-se dessa fala uma possibilidade interessante de trabalho pedagógico junto aos alunos que, em certa medida, também está presente nos outros filmes. Refere-se à questão do desenvolvimento da empatia, dado que ela 
é uma possibilidade do desenvolvimento humano, não apenas por meio da educação escolar, mas da educação em geral, cujo resultado é a capacidade de compreensão do outro, por meio da tentativa de se colocar em seu lugar (Dilthey, 2010; Krznaric, 2013).

Um último filme que tem sido utilizado em sala de aula é The Great Debaters (2007, no Brasil, O grande desafio). Foi dirigido por Denzel Washington, com roteiro de Jeffrey Porro e Robert Eisele. Baseia-se em fatos, com destaque para a narrativa sobre a juventude de James Leonard Farmer Jr., que se tornaria ativista dos direitos civis, tendo liderado a criação, em 1961, da Freedom Ride, importante organização de luta pelos direitos civis nos Estados Unidos. Além de dirigir o filme, Denzel Washington, com Oprah Winfrey, Joe Roth, Bob Weinstein e Harvey Weinstein, esteve à frente de sua produção. Integraram o elenco: Denzel Washington (Melvin. B. Tolson), Forest Whitaker (James L. Farmer Jr), Denzel Whitaker (James L. Farmer, Jr), Nate Parker (Henry Lowe), Jurnee Smollett (Samantha Booke) e Jermaine Williams (Hamilton Burgess).

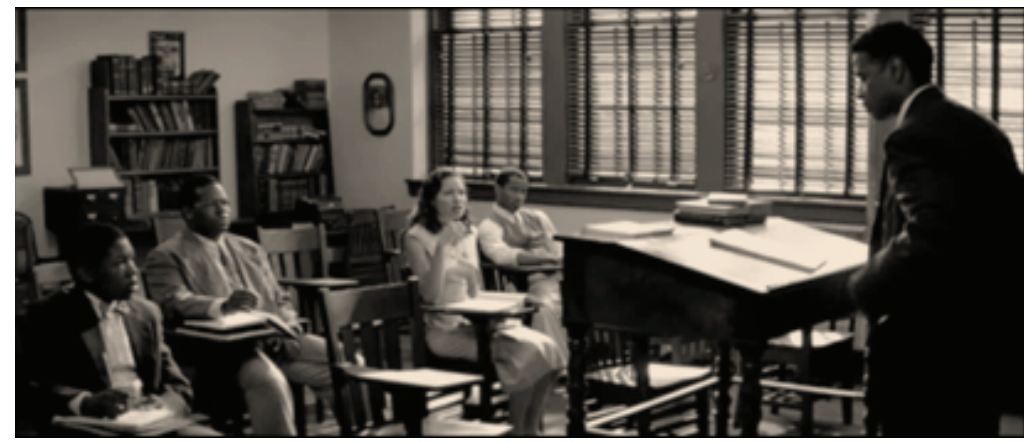

Figura 5 - Cena de O grande desafio (2007) em que

Melvin B. Tolson (Denzel Washington) instrui seus alunos em sala de aula do Wiley College (Faculdade Wiley), na época exclusivamente para alunos negros.

O filme aborda a história de um grupo de alunos debatedores da Faculdade Wiley (Wiley College) treinados por Melvin B. Tolson, e as dificuldades e vitórias que tiveram nos debates realizados com alunos de instituições de educação superior exclusivamente para brancos. Em uma das cenas iniciais, ao repreender um dos membros do grupo de debatedores que não está levando a 
sério a atividade, o treinador disserta sobre a situação de seus antepassados e a oportunidade que o jovem está perdendo:

Melvin B. Tolson: Manter o escravo fisicamente forte, mas psicologicamente fraco e dependente do capataz. Manter o corpo, dominar a mente. Eu e todos os professores deste campus estamos aqui para ajudá-lo a encontrar, recuperar e manter sua mente, porque, obviamente, você a perdeu.

Outro momento do filme é um debate promovido entre os alunos da Faculdade Wiley com alunos de uma faculdade para alunos brancos. O local é uma tenda armada em um bosque, em razão da resistência em promovê-lo no campus de uso exclusivo de alunos brancos. O debate é em torno do ingresso de alunos negros em faculdades exclusivamente para brancos, com defesa, pelos alunos brancos, da impossibilidade de isso vir a acontecer no curto e médio prazo. Estes recebem esta resposta da aluna que debatia pela Faculdade Wiley:

Samantha Booke: ... meu adversário diz que hoje não é o dia de brancos e negros frequentarem a mesma faculdade, dividir o mesmo campus, entrarem na mesma sala de aula. Vocês poderiam me dizer quando esse dia vai chegar? Será amanhã? Será na semana que vem? Daqui a cem anos? Nunca? Não, o momento da justiça, o momento da liberdade, o momento da igualdade é sempre agora!

Na sequência, os alunos debatedores da Faculdade Wiley são convidados a debater com os alunos da Universidade Harvard, em Cambridge, Massachusetts, no edifício Memorial Hall, no campus da universidade. No debate lá travado, Samantha Booke e James L. Farmer Jr. conseguiram vencer os debatedores da Universidade Harvard, e reproduzimos o diálogo principal apresentado no filme:

Debatedor de Harvard: A não violência é a máscara que a desobediência civil usa para esconder a sua verdadeira face: a anarquia.

Samantha Booke: Por que um cidadão deveria render sua consciência a um legislador? Não, não devemos nos ajoelhar nunca diante da tirania de uma maioria.

Debatedor de Harvard: ... A beleza e o fardo da democracia é que nenhuma ideia prevalece sem o apoio da maioria ... Nada que corroa a lei pode ser moral. Não importa o nome que tenha. 
James L. Farmer, Jr.: No Texas eles lincham negros. Qual foi o crime daquele negro para ele ser enforcado sem julgamento, em uma floresta escura, cheia de névoa? Era um ladrão? Um assassino, ou apenas um negro? ... Os filhos estavam esperando por ele? ... Não importa o que ele tenha feito, quem cometeu o crime foi o grupo. Mas a lei não fez nada, só nos deixou perguntando: por quê? ... não há leis no Sul de Jim Crow, não quando negros não podem ter casas, quando são rejeitados em escolas, hospitais, e não quando somos linchados ... Uma lei injusta não é lei. O que significa que eu tenho o direito, até o dever, de resistir com violência ou desobediência civil. Vocês deveriam agradecer por eu escolher a última.

A exibição desse filme tem um efeito muito positivo nos debates que ocorrem em sala de aula, dado que evidencia a problemática do racismo e enfatiza a política de segregação racial existente nos Estados Unidos, em uma época próxima à promulgação, pelas Nações Unidas, da Declaração Universal dos Direitos Humanos, em 1948. Isso denota os elementos de resistência à doutrina dos direitos humanos, com dificuldades oriundas de legislação que legitimava e favorecia a permanência do racismo e da desigualdade de cunho racial. Além disso, chama a atenção para as estratégias de caráter pacifista de movimentos da sociedade civil na luta pelos direitos humanos.

Assim, a primeira unidade da disciplina de História da Educação nos cursos de licenciatura da UFU, excetuando o de Pedagogia, nos quais tenho atuado nos últimos anos, tem-se beneficiado do cotejamento entre as ideias e as ações que fomentaram a construção de uma sociedade de direitos, nos marcos da doutrina dos direitos humanos, com uma série de filmes de massa norte-americanos. São filmes que se esforçam em demonstrar aspectos dessa legislação, em situações ficcionais e mesmo em filmes que se baseiam em fatos.

É evidente que muitos outros filmes poderiam ser utilizados, o que inclui produções brasileiras, e isso provavelmente poderá acontecer, mas, neste momento, a escolha recaiu em função da facilidade de aquisição no formato DVD e da abrangência mundial que alcançaram.

No que se refere à segunda unidade da disciplina, intitulada "Escolarização, civilização e estratégias de inclusão diferenciada", a ênfase recai sobre a compreensão do desenvolvimento da vida em sociedade ao longo do século XX. Para tanto, são utilizados dois textos bastante densos. Os alunos procedem a uma leitura guiada por um conjunto de questões elaboradas pelo professor, as quais favorecem os debates que ocorrerão em sala de aula. 
O primeiro texto utilizado é o de Antoine Prost, intitulado “A família e o indivíduo", em edição datada de 1992, como parte do quinto volume de uma obra mais extensa, organizada pelo próprio Antoine Prost e por Gérard Vincent, intitulada, História da vida privada. Há nesse texto um esforço de percepção do nascimento de uma vida pública profissional, com análise do empreendimento escolar e dos empreendimentos educativos provenientes de diversas agências educativas não escolares. Por vezes, no tratamento desse conteúdo, é possível introduzir a exibição de um filme intitulado Au Revoir les Infants (1987; no Brasil, Adeus meninos), com produção, roteiro e direção de Louis Malle, baseado nas lembranças do próprio diretor sobre uma escola católica francesa que, durante a ocupação nazista, escondeu alguns alunos judeus. $\mathrm{Na}$ disciplina, além da história que se passa no universo escolar da época e na emoção provocada pela empatia dos alunos pelos personagens, há elementos que permitem vislumbrar o cotidiano da vida na época.

Na sequência, insiste-se um pouco na forma tomada pela educação na década de 1930, em especial no registro alemão, na vertente nazista, na qual a juventude hitlerista congrega cada vez mais afiliados, enquanto outros grupos de jovens adotam caminhos alternativos e opõem-se aos hitleristas. Para tanto, parte-se da leitura e da resposta pelos alunos a algumas questões, elaboradas por mim, ao texto de Eric Michaud, intitulado "Soldados de uma ideia: os jovens sob o Terceiro Reich", publicado em português em 1996, no interior do segundo volume da obra organizada por Giovanni Levi e Jean-Claude Schmitt, nomeada História dos jovens. É um texto denso, que esmiúça o espírito que presidia a juventude hitlerista, seus ideais, suas principais práticas organizativas e educativas.

Quase sempre, tem sido possível associar ao trabalho com esse excelente texto a exibição de um filme muito interessante, que se passa em Hamburgo no ano de 1939, no qual se evidenciam polarizações entre a juventude hitlerista e outros grupos de jovens, notadamente, no caso do filme, da chamada juventude swing, que adotava a língua e os trajes ingleses e preferia o jazz, a música hot e o swing. Trata-se do filme Swing Kids (1993; no Brasil, Os últimos rebeldes). Sem dúvida, texto e filme colaboram sobremaneira para a compreensão dos fundamentos da doutrina dos direitos humanos e do combate que ela comporta em relação a uma visão de mundo preconizada pelo Estado Racial, 
conforme proposto pelos nazistas e disseminado em termos pedagógicos e ideológicos no seio da juventude hitlerista.

Nessas duas primeiras unidades, o impulso que tem movido a disciplina de História da Educação está relacionado à compreensão da modernidade, sua relação com a sociedade e o papel da educação, em especial, em sua forma escolar, na direção de perceber os avanços e recuos da doutrina dos direitos humanos, até o momento dos principais conflitos do século XX. Aparentemente, o conteúdo tem oportunizado, aos alunos, a compreensão dos princípios fundamentais de uma sociedade livre e em busca de maior equalização social, distante de preconceitos, que valorize o papel da educação e da escola nesse processo.

\section{Os PROCESSOS DE ESCOLARIZAÇÃo No BRASIL, em Minas Gerais E no Triângulo Mineiro}

Após o trabalho com as duas primeiras unidades da disciplina de História da Educação, que tomam quase sempre mais de 2 meses das aulas, parte-se para a abordagem do processo de modernização e de escolarização no Brasil, com exame particular da situação vivenciada na cidade de Uberlândia, onde funcionam os cursos e onde nasceu a maior parte dos alunos.

Nesse sentido, dois fatores contam a favor do desenvolvimento das aulas. Primeiramente, a existência de um importante acervo fotográfico no Centro de Documentação e Pesquisa em História (CDHIS) da UFU, no qual há centenas de imagens relacionadas às instituições escolares da cidade de Uberlândia e que têm sido utilizadas no ensino da disciplina, não só pelo seu caráter ilustrativo de épocas passadas, mas também pelas possibilidades de problematização de temas históricos, educacionais e sociais que elas suscitam. Nessa direção, destaca-se o acervo João Quituba, devidamente inventariado (Cardoso; Rodrigues; Machado, 1989), que reúne 2.595 documentos datados de 1851 a 1981 (Uberlândia, 2015a). Outro acervo fotográfico valioso encontra-se no Arquivo Público Municipal de Uberlândia, que reúne aproximadamente 18 mil fotografias, com destaque para o acervo da coleção nomeada "Jerônimo Arantes: jornais da cidade desde 1907, revistas, fotografias e clichês", que contém muitas imagens acerca das escolas rurais da cidade (Uberlândia, 2015b). Por fim, há ainda imagens fotográficas que estão nos arquivos das instituições 
escolares e em arquivos particulares, e que aparecem em inúmeras dissertações e teses sobre a História das Instituições Escolares defendidas, principalmente, no âmbito da linha de pesquisa em História e Historiografia da Educação do Programa de Pós-Graduação em Educação da UFU. Exemplos de imagens que são utilizadas em sala de aula e que constam desses acervos estão apresentados nas figuras expostas a seguir. ${ }^{6}$

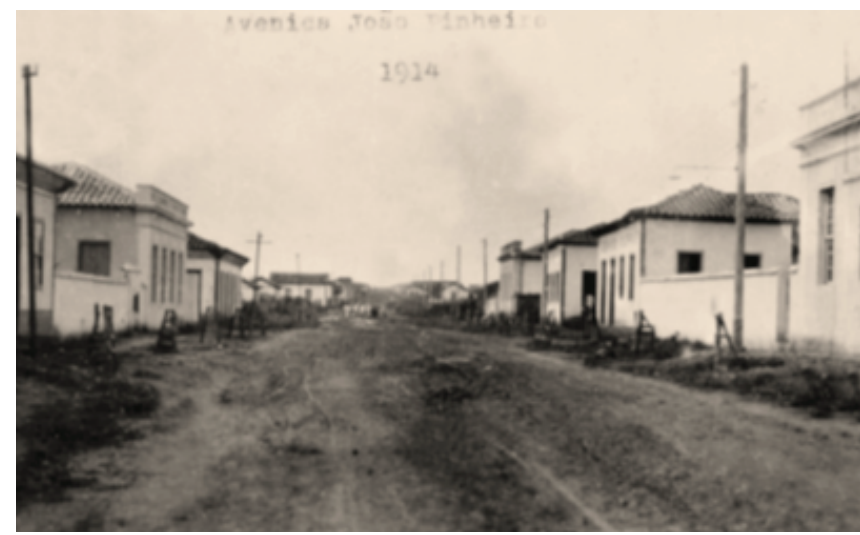

Figura 6 - Avenida João Pinheiro, em Uberlândia, MG (1914). Fonte: Acervo João Quituba do CDHIS/UFU (JQ0044).

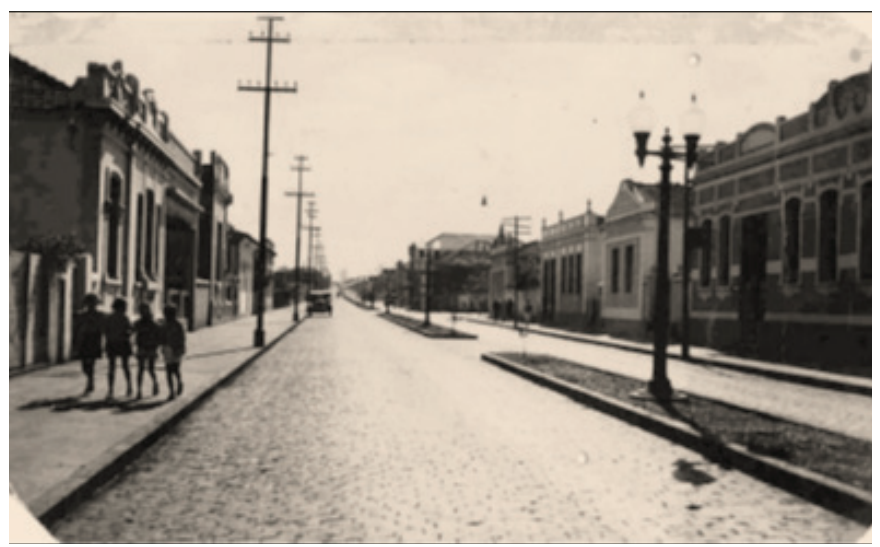

Figura 7 - Avenida João Pinheiro, em Uberlândia, MG (1940). Fonte: Acervo João Quituba do CDHIS/UFU (JQ0013). 


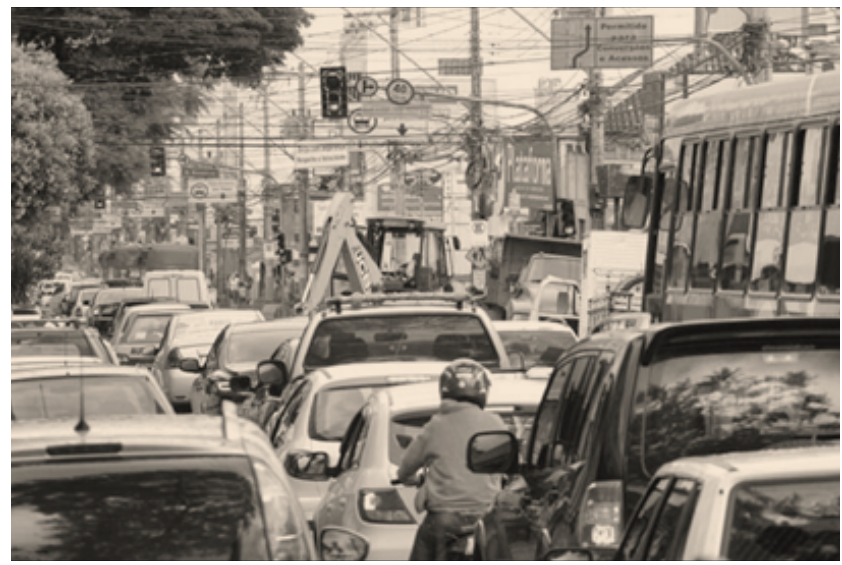

Figura 8 - Avenida João Pinheiro, em Uberlândia, MG (2013). Fonte: Correio de Uberlândia (2013).

O conjunto de imagens contido nas Figuras 6, 7 e 8 possibilita observar o processo de modernização, em especial, no que se refere à urbanização, vivenciado em Uberlândia no século XX, favorecendo o debate, junto aos alunos, de questões relacionadas aos efeitos da intervenção humana na área urbana, notadamente as consequências oriundas da deficiência do planejamento na cidade, o que se repete em diversas outras do Brasil.

Quanto à Figura 9, tem sido interessante observar a reação dos alunos à maneira como as normalistas, que se formaram em um importante colégio católico que ainda se encontra em atividade, estão dispostas e vestidas, bem como o fato de crianças pequenas comporem a imagem. Aqui, tem sido aproveitada a discussão possível sobre a entrada da mulher no ofício docente da escola primária, bem como sobre o papel das instituições escolares confessionais na formação dessas professoras, com impacto para os processos de laicização do ensino, quase sempre incipientes na escola pública mineira da época em referência. 


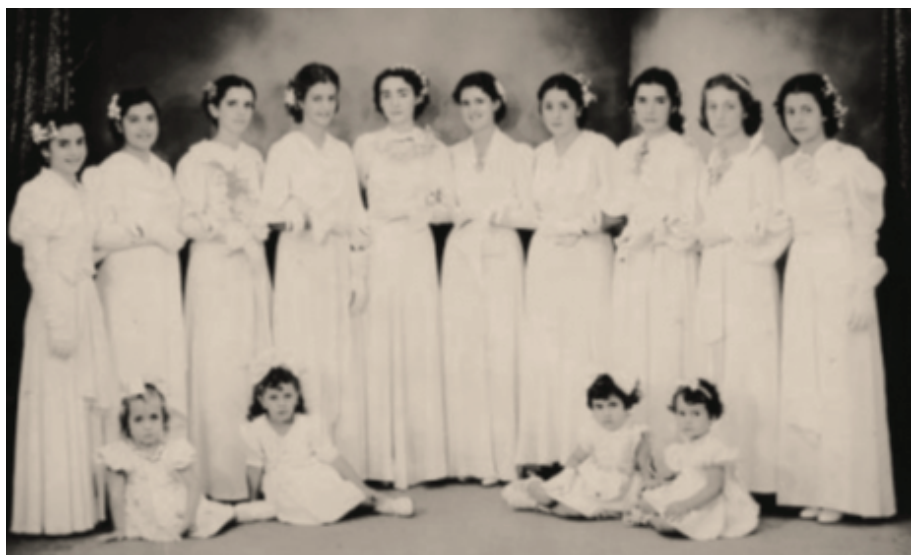

Figura 9 - Formandas do Colégio Nossa Senhora das Lágrimas, em Uberlândia, MG (1937).Fonte: Acervo João Quituba do CDHIS/UFU (JQ1956).

Percebe-se outro aspecto interessante nas Figuras 10, 11 e 12, que ilustram a passagem de uma instituição escolar pioneira, funcionando em espaço improvisado, para uma instituição em busca de consolidação, com a construção de um prédio monumental, na época, e, por fim, na atualidade, com a escola ocupando um lugar diferente na vida da cidade (Gatti, 2013; Gatti; Inácio Filho; Gatti Jr., 2015).

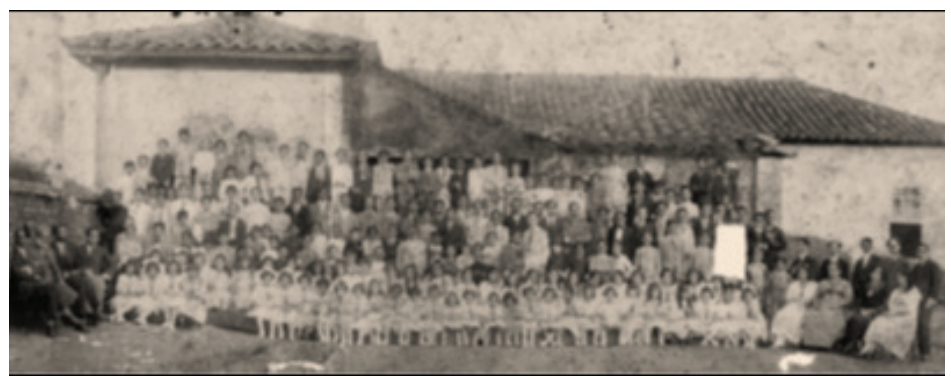

Figura 10 - Gymnásio de Uberabinha. Praça da República, hoje Praça Tubal Vilela (1919).

Fonte: Acervo João Quituba do CDHIS/UFU (JQ807). 


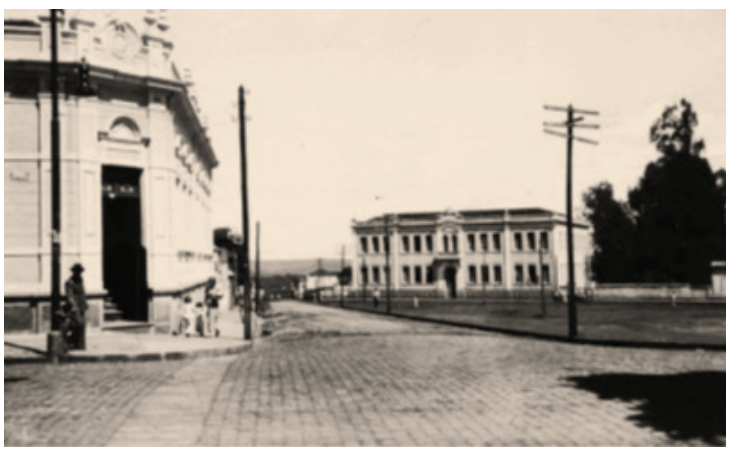

Figura 11 - Praça Adolfo Fonseca. Grande Hotel e Gymnásio Mineiro (1930). Fonte: Acervo João Quituba do CDHIS/UFU (JQ0442).

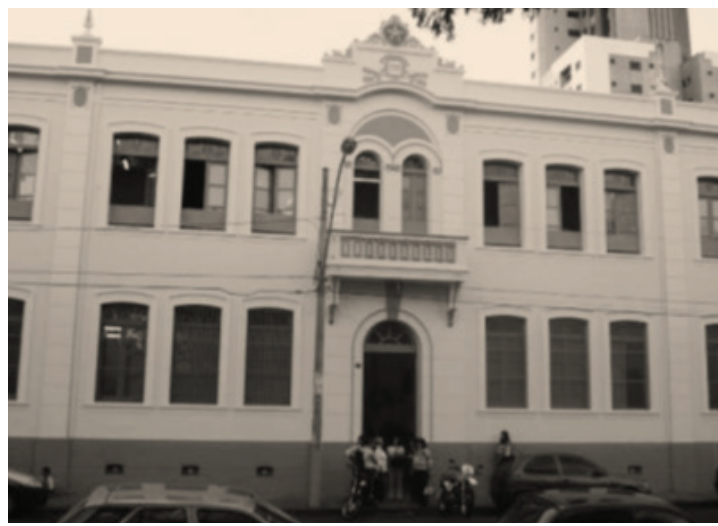

Figura 12 - Fachada da Escola Estadual Uberlândia (2007). Fonte: Fotografia de Giseli Cristina do Vale Gatti.

As imagens presentes nas Figuras 13 e 14 permitem perceber o caráter cívico e patriótico presente nas instituições escolares da cidade de Uberlândia, o que, de fato, estendia-se por todo o país como expressão de uma das grandes finalidades contidas no espírito e na legislação educacional da época, que encontrava forte correspondência no Colégio Estadual de Uberlândia, em especial, entre as décadas de 1930 e 1970. 


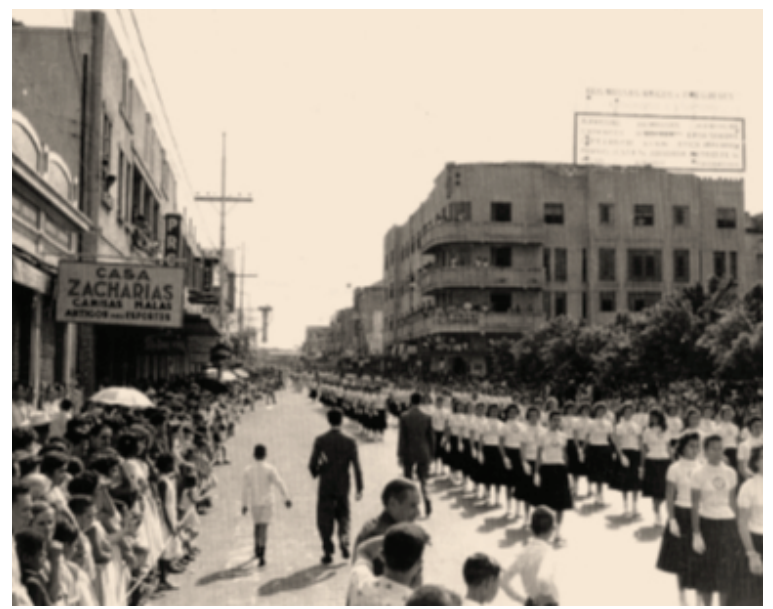

Figura 13 - Desfile Cívico do Sete de Setembro pelo Colégio Estadual de Uberlândia (s.d.).

Fonte: Acervo da Escola Estadual de Uberlândia.

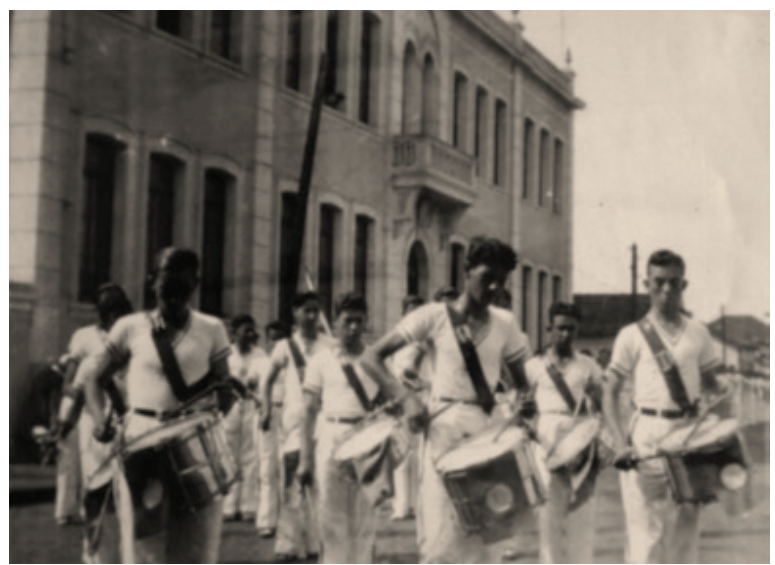

Figura 14 - Fanfarra do Colégio Estadual de Uberlândia, na década de 1940. Fonte: Acervo da Escola Estadual de Uberlândia, 1940.

Outro aspecto interessante está relacionado aos uniformes escolares, que denotam finalidades educacionais mais amplas, vinculadas ao espírito de uma época e à legislação de ensino que lhe confere organicidade. Exemplo interessante pode ser observado nas fotografias extraídas de acervo particular de uma 
ex-aluna do Ginásio, Sra. Isolina Cupertino, conforme exposto nas Figuras 15 e 16. Na primeira imagem, de 1929, vivia-se um período democrático; na segunda, de 1937, vivia-se sob a ditadura de Getúlio Vargas.

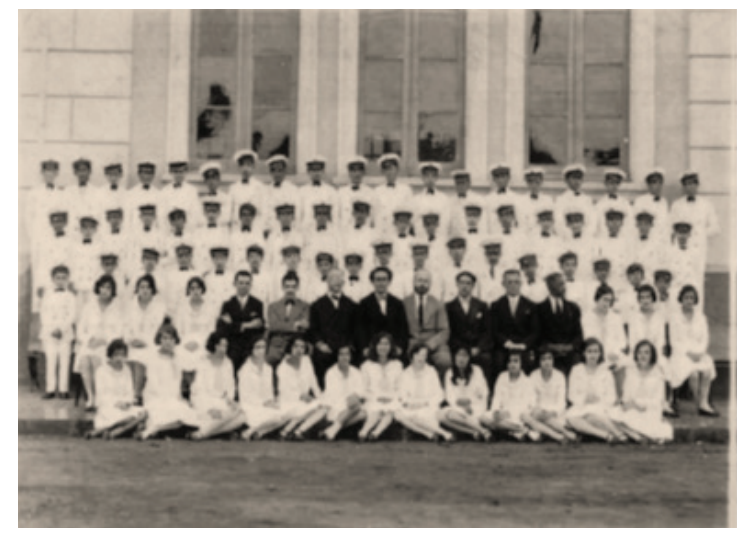

Figura 15 - Alunos, professores e diretor, Dr. Mário Porto, no Gymnásio Mineiro de Uberlândia (1929).

Fonte: Acervo Particular da Sra. Isolina Cupertino.

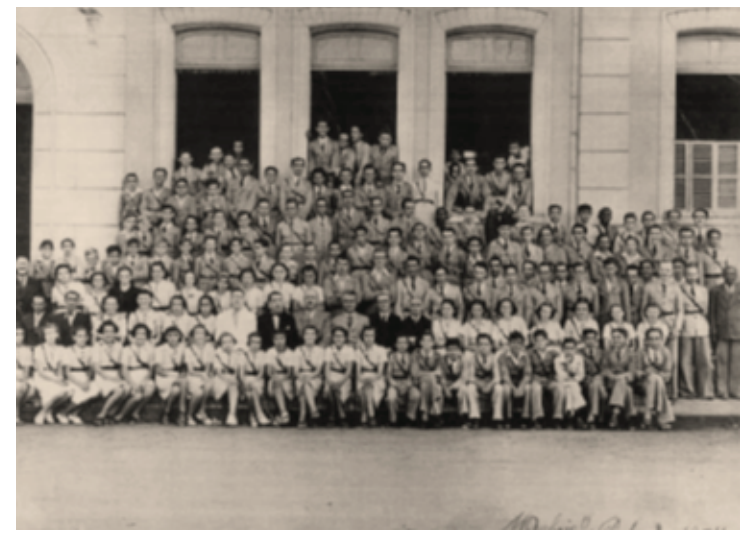

Figura 16 - Estudantes, professores e dirigentes do Gymnásio Mineiro de Uberlândia (1937).

Fonte: Acervo particular da Sra. Isolina Cupertino.

No caso da terceira e última unidade do programa da disciplina de História da Educação, o trabalho tem início com a exposição e o debate dessas e de uma série de outras imagens da cidade de Uberlândia e da região do 
Triângulo Mineiro, como forma de estímulo aos alunos, pelo reconhecimento de lugares que frequentaram e que ainda frequentam cotidianamente, ainda que desconhecendo o que seus antepassados faziam. Felizmente, isso tem funcionado, tornando mais fácil o trabalho com os textos produzidos na sequência. Os textos compreendem, inicialmente, a leitura de um texto de cunho mais geral, escrito por dois experientes pesquisadores da História da Educação, Luciano Faria Filho e Diana Gonçalves Vidal. Trata-se de "Os tempos e os espaços escolares no processo de institucionalização da escola primária no Brasil”, publicado no ano 2000, que aborda o processo de implantação escolar no Brasil em meio à modernização pela qual passava o país, com desdobramentos na edificação de prédios escolares, em associação com mudanças das finalidades educacionais postas ao longo da História. Texto que permite proveitoso debate e o reconhecimento de semelhanças entre o que se passou na cidade de Uberlândia, na região do Triângulo Mineiro e no restante do país. Em seguida, três textos contribuem para aprofundar o entendimento dos processos de escolarização na cidade de Uberlândia, tratando respectivamente das seguintes instituições escolares: o Grupo Escolar Júlio Bueno Brandão (Carvalho; Carvalho, 2003); o Gymnásio Mineiro de Uberlândia (Gatti; Inácio Filho, 2011), e o Colégio Nossa Senhora das Lágrimas (Ramos, 2002).

\section{CONSIDERAÇÕES FINAIS}

Os resultados dessa experiência de ensino não passaram ainda por uma avaliação externa. No entanto, a avaliação interna permite afirmar que a experiência tem sido positiva, tanto pela mudança na visão dos alunos sobre a disciplina e no aumento do envolvimento e do interesse nas aulas, quanto pelo que se observa nos momentos de encerramento da matéria. Os alunos manifestam suas impressões frisando que gostaram da disciplina, revendo a opinião que tinham quanto ao seu conteúdo, colocando-a entre as melhores do semestre letivo.

Com esses resultados, é possível inferir que a seleção do conteúdo a ser trabalhado - em uma perspectiva que confere unidade e sentido à questão da escolarização como efeito da modernidade, aproveitando-se de recursos tecnológicos e de fontes imagéticas, tais como a fotografia e o cinema - tem favorecido o trabalho pedagógico e a aprendizagem no âmbito da disciplina 
História da Educação. O tempo dispensado à disciplina é curto, 60 horas em um semestre letivo, mas o esforço em criar empatia entre os alunos e os personagens que habitavam e habitam as escolas tem surtido resultados positivos, que têm servido de estímulo ao trabalho docente, o que, ao se considerar a situação docente e do ensino escolar na atualidade, não parece pouco!

\section{REFERÊNCIAS}

BITTENCOURT, Circe Maria Fernandes. Ensino de História: fundamentos e métodos. 3.ed. São Paulo: Cortez, 2009.

BORGES, Maria Eliza Linhares. História \& Fotografia. 2.ed. rev. Belo Horizonte: Autêntica, 2005.

CARDOSO, Heloisa Helena Pacheco; RODRIGUES, Jane de Fátima Silva; MACHADO, Maria Clara Tomaz. Inventário da coleção "João Quituba". Uberlândia, MG: Universidade Federal de Uberlândia/ Núcleo de Pesquisa e Documentação em História e Ciências Sociais, 1989.

CARVALHO, Luciana Beatriz de Oliveira Bar de; CARVALHO, Carlos Henrique. As singularidades do Grupo Escolar Júlio Bueno Brandão no processo da construção da Modernidade (Uberabinha/MG, 1915-1929). Cadernos de História da Educação, v.2, p.129-139, 2003.

DILTHEY, Wilhelm. A compreensão de outras pessoas e as suas manifestações vitais. In: . A construção do mundo histórico nas ciências humanas. Trad. Marco Casanova. São Paulo: Ed. Unesp, 2010. (Clássicos Unesp).

FARIA FILHO, Luciano; VIDAL, Diana Gonçalves. Os tempos e os espaços escolares no processo de institucionalização da escola primária no Brasil. Revista Brasileira de Educação, n.14, p.19-34, 2000. Disponível em: http://www.redalyc.org/articulo. oa? $\mathrm{id}=27501403$.

FERRO, Marc. O filme. Uma contra-análise da sociedade? In: LE GOFF, Jacques; NORA, Pierre. Fazer História. 3 Novos Objetos. Venda Nova: Bertrand, 1987. p.255276.

GATTI, Giseli Cristina do Vale. A escola e a vida na cidade: o Gymnásio Mineiro de Uberlândia (1929-1950). Uberlândia: Edufu, 2013.

GATTI, Giseli Cristina do Vale; INÁCIO FILHO, Geraldo. Cidade urbanizada e o espaço escolar do Gymnásio Mineiro de Uberlândia de fins do século XIX e a primeira metade do século XX. Cadernos de História da Educação, v.10, n.1, p.93121, 2011.

GATTI, Giseli Cristina do Vale; INÁCIO FILHO, Geraldo; GATTI JR., Décio. A escola e a vida na cidade em dois tempos: o Ginásio Mineiro de Uberlândia entre as décadas de 1930 e de 2000. In: CATANI, Denice Barbara; GATTI JR., Décio (Org.) 
O que a escola faz? Elementos para a compreensão da vida escolar. Uberlândia: Edufu, 2015. p.145-169.

GATTI JR., Décio. A construção de uma sociedade de direitos: história, livro didático e cinema. Uberlândia: Universidade Federal de Uberlândia, 2010. 20p.

. Em busca da articulação entre compreensão empática, sensibilidade e dimensão dialógica: contribuições para o ensino da história no ensino médio brasileiro. Perspectiva, Florianópolis: UFSC, v.32, n.2, p.475-495, 2014.

GATTI JR., Décio; INÁCIO FILHO, Geraldo; ARAÚJO, José Carlos Souza; GONÇALVES NETO, Wenceslau. História e memória educacional: gênese e consolidação do ensino escolar no Triângulo Mineiro. História da Educação, Pelotas: UFPel, v.1, n.2, p.5-28, 1997.

HUNT, Lynn. A invenção dos direitos humanos: uma história. São Paulo: Companhia das Letras, 2009.

KRZNARIC, Roman. Empatia. In: Sobre a arte de viver: lições da história para uma vida melhor. Trad. Maria Luiza X. de Borges. Rio de Janeiro: Zahar, 2013. p.68-92.

MICHAUD, Eric. Soldados de uma ideia: os jovens sob o Terceiro Reich. In: LEVI, Giovanni; SCHMITT, Jean-Claude. História dos jovens, v.2: a época contemporânea. São Paulo: Companhia das Letras, 1996. p.291-317.

PROST, Antoine. A família e o indivíduo. In: PROST, Antoine; VINCENT, Gérard (Org.) História da vida privada, v.5: da Primeira Guerra a nossos dias. São Paulo: Companhia das Letras, 1992. p.61-113.

RAMOS, Lucélia C.; INÁCIO FILHO, Geraldo. A atuação da Igreja Católica na educação uberlandense: o Colégio Nossa Senhora das Lágrimas. Cadernos de História da Educação, v.1, p.67-72, 2002.

TOURAINE, Alain. Crítica da Modernidade. 10.ed. Petrópolis, RJ: Vozes, 2012.

UBERLÂNDIA. Arquivo Público Municipal. Disponível em: http://www.uberlandia. mg.gov.br/2014/secretaria-pagina/23/327/arquivo_publico_de_uberlandia.html; Acesso em: 22 ago. 2015b.

UBERLÂNDIA. Inventário de Proteção do Acervo Cultural, Minas Gerais, Brasil. Fontes Arquivistas. João Quituba. Disponível em: http://www.uberlandia.mg.gov.br/ uploads/cms_b_arquivos/6196.pdf; Acesso em: 22 ago. 2015a.

\section{Filmes}

A MULHER faz o homem. Direção e produção: Frank Capra. Estados Unidos: Columbia Pictures, 1939. 1 DVD (130 min).

ADEUS meninos. Direção: Louis Malle. Produção: Nouvelles Éditions de Films; Stella 
Films; NEF Filmproduktion; França/Alemanha: MK2 Diffusion, 1987. 1 DVD (104 min).

DOZE Homens e uma sentença. Direção: Sidney Lumet. Produção: Henri Fonda e Reginald Rose. EUA: Orion-Nova, 1957. 1 DVD (96 min).

FILADÉLFIA. Direção e produção: Jonathan Demme. EUA: Tristar, 1993. 1 DVD (128 min).

O GRANDE desafio. Direção: Denzel Washington. Produção: Oprah Winfrey et al. EUA: Harpo Productions; The Weinstein Company, 2007. 1 DVD (126 min).

OS ÚLTIMOS rebeldes. Direção: Thomas Carter. Produção: Mark Gordon e John Bard Manulis. EUA: Hollywood Pictures; Buena Vista Pictures, 1993. 1 DVD (114 $\min )$.

TEMPO de matar. Direção: Joel Schumacher. Produção: Arnon Milchan, John Grisham, Michael Nathanson e Hunt Lowry. EUA: Regency Entreprises; Warner Bros, 1996. 1 DVD (149 min).

\section{NOTAS}

${ }^{1}$ Doutor em Educação: História e Filosofia da Educação pela Pontifícia Universidade Católica de São Paulo (PUC-SP), com estágio de pós-doutorado concluído na Faculdade de Educação da Universidade de São Paulo (USP). Professor Titular de História da Educação da Faculdade de Educação da Universidade Federal de Uberlândia (UFU), na qual coordena o Grupo de Estudos e Pesquisas sobre a Disciplina História da Educação, edita o periódico Cadernos de História da Educação e coordena a coleção de livros "História, Pensamento e Educação". Bolsista de Produtividade em Pesquisa do Conselho Nacional de Desenvolvimento Científico e Tecnológico (CNPq). Beneficiário do Programa Pesquisador Mineiro da Fundação de Amparo à Pesquisa do Estado de Minas Gerais (Faperj).

${ }^{2} \mathrm{O}$ termo Modernidade é compreendido aqui na acepção apontada por Touraine (2012), na qual há uma concepção clássica de modernidade, em que a racionalização suplanta e até silencia a subjetivação em nome do predomínio de uma consciência coletiva sobre a consciência individual, mas, também, na qual há uma proposição de construção da Modernidade em termos da permanente tensão entre racionalização e subjetivação, com a ideia de que Estado e Sociedade Civil não se identificam, mas, pelo contrário, movem-se na difícil direção de conciliar o interesse individual e o bem comum.

${ }^{3} \mathrm{O}$ historiador Marc Ferro que, entre outros temas, estudou os filmes de propaganda soviética e antissoviética, tomou o cinema com um novo e importante objeto histórico, levando em conta seu caráter fascinante e seus efeitos, por vezes, corrosivos, mas, sobretudo, considerando que o "filme é observado, não como uma obra de arte, mas como um produto, uma imagem-objeto, cujas significações não são unicamente cinematográficas. Ele vale por aquilo que testemunha" (FERRO, 1987, p.260). 
${ }^{4}$ Nesse sentido, o trabalho desenvolvido em sala de aula buscou inspiração na forma como a historiadora Lynn Hunt (2009) abordou a temática dos direitos humanos, por meio da conjugação de informação e análise histórica que, além dos documentos mais diretamente relacionados à doutrina do direitos humanos, elaborados no final do século XVIII, também procedeu a análise da relação entre a literatura e as artes plásticas no que se refere às ideias sobre os direitos humanos. Como decorrência, manteve-se na disciplina o estudo dos documentos históricos relacionados à doutrina dos direitos humanos, bem como o estudo sobre o contexto histórico subjacente e sobre os princípios que os direitos humanos comportam, trazendo, porém, a análise da forma de disseminação dos direitos humanos no âmbito do cinema, manifestação cultural típica do século XX e que se estende até o presente, ainda que em diferentes suportes, com a consideração importante de ter caráter cada vez mais global.

${ }^{5}$ Nesse sentido, na análise dos filmes em sala de aula, usualmente, temos seguido um roteiro bastante interessante apresentado em BITTENCOURT (2009, p.375), que leva em consideração três aspectos fundamentais para a análise dos filmes, resumidamente: o conhecimento dos elementos que compõem seu conteúdo; a compreensão do contexto social e político que envolveu a produção do filme; a forma como o filme foi recepcionado pela crítica e pelo público.

${ }^{6}$ Para o aprofundamento da relação entre fotografia e História recomenda-se a leitura de BORGES (2005).

Artigo recebido em 15 de agosto de 2015. Aprovado em 6 de dezembro de 2015. 